\title{
Type of anaesthesia for caesarean section and failure rate in Princess Marina Hospital, Botswana's largest referral hospital
}

\author{
Mamo W Kassa ${ }^{1}$, Jack J Mkubwa ${ }^{2}$, Jemal Z Shifa ${ }^{3}$, Tefera B Agizew ${ }^{4}$
}

1. Department of Anaesthesia and Critical Care, University of Botswana, Botswana.

2. Department of intensive care unit Princess Marina Hospital, Ministry of Health.

3. Department of Surgery, University of Botswana, Botswana.

4. Department of Family Medicine and Public Health, University of Botswana.

\begin{abstract} (SA) in Princess Marina Referral Hospital, Botswana.

Keywords: Caesarean section, types of anaesthesia, spinal failure.

DOI: https://dx.doi.org/10.4314/ahs.v20i3.26 abs.v20i3.26

\section{Introduction}

Cesarean section (CS) is one mode of delivering a newborn using a surgical intervention mainly meant to decrease maternal and perinatal morbidity and mortality ${ }^{1,2}$. Globally the rate of CS is increasing both in high- and low-income countries ${ }^{2-4}$. Recently, governments and clinicians have expressed concern about the rise in the numbers of CS births and the potential negative consequences for maternal and infant health ${ }^{5-8}$. The increase has two main reasons: maternal preference ${ }^{9}$ and an increase in emergency CS attributed to advanced intrapartum fetal monitoring ${ }^{10}$. The latter allows obstetricians to diagnose intrapartum fetal compromise earlier and more effectively ${ }^{10}$.
\end{abstract}

Background: Caesarean Section (CS) is a mode of delivery to decrease maternal and perinatal morbidity and mortality. We aimed to determine the type of anaesthesia used for CS among live-birth deliveries; and the failure rate of spinal anaesthesia

Methods: Women who underwent CS from May-December 2017 were enrolled in the study. Data were recorded from anaesthesia charts and abstracted using Excel spreadsheet. We established the type of anaesthesia used, comparing the rate of elective versus emergency indications, and failure rate of SA using STATA. Fisher's exact test used to compare results.

Results: Among 2775 live-birth deliveries, 30.2\% (837/2775) was by CS. Of those, 95.2\% (797/837) had had SA and 4.8\% (40/837) were GA. Under SA, 27.4\% (218/797) were elective, and 72.6\% (579/797) were emergency. Under GA 10\% (4/40) were elective and $90.0 \%(36 / 40)$ were emergency. The overall failure rate of SA was $2 \%(16 / 813)$, that is $0.9 \%(2 / 220)$ for elective and 2.4\% (14/593) among emergency indications; Fisher's exact test $\mathrm{p}=0.2959$.

Conclusion: Our study demonstrated that single shot SA is the most commonly preferred type of anaesthesia for both elective and emergency CS. The overall failure rate of SA was less common in our settings than previously reported.

Cite as: Kassa MW, Mkubwa JJ, Shifa JZ, Agizew TB. Type of anaesthesia for caesarean section and failure rate in Princess Marina Hospital, Botswana's largest referral hospital. Afri Health Sci.2020;20(3): 1229-1236. https:/ / dx.doi.org/10.4314/

\section{Corresponding author:}

Mamo W Kassa

4775 Notwane Road, Gaborone, Botswana

Emailmwoldu@ymail.com
There are two types of anaesthesia for CS, regional (spinal anaesthesia, epidural anaesthesia, and combined spinal-epidural anaesthesia) and general anaesthesia ${ }^{11}$. Current evidence highlights the benefits and increased use of regional over general anaesthesia for CS since regional anaesthesia avoids the risk of difficult intubation, pulmonary aspiration of gastric contents, minimal blood loss and helps to avoid the use of multiple drugs that may cause drug interactions with drugs used for general anaesthesia ${ }^{10-13}$. Furthermore, there is an increased tendency of using CS under regional anaesthesia because of the risk of failed intubation and aspiration of gastric contents that are causes of maternal morbidity and mortality ${ }^{14}$.

Though both regional and general anaesthesia are acceptable for CS the use of general anaesthesia has fallen dramatically in high-income countries in the past few decades and is now used in less than $5 \%$ of CS $^{14-16}$. The type of anaesthesia chosen for CS is dependent on numerous factors such as the urgency, indication of the 
operation, coexisting medical problems, maternal and obstetrician's preference, anticipated duration and difficulty of the procedure and the presence or absence of an in-situ epidural or spinal catheter ${ }^{17-19}$. There are many indications for general anaesthesia, some of which are failed regional anaesthesia, conditions where regional anaesthesia is contraindicated, maternal request and life-threatening fetal and/or maternal compromise that may occur with extra time incurred with a regional technique or where there is insufficient time for a regional technique ${ }^{20}$.

Data on the type of anaesthesia by urgency, elective and emergency, and prevalence of CS are limited, especially in low-income countries. In the United States and the UK, general anaesthesia is used for less than $5 \%$ of elective CS deliveries. For emergency CS deliveries, the rate varies between 15 and $30 \%{ }^{16}$. In sub-Saharan Africa, $10-20 \%$ of the CS are performed under general anaesthesia ${ }^{21}$. There is no internationally accepted classification system for CS. The international healthcare community has considered the ideal rate for CS to be between $10 \%$ and $15 \%{ }^{22}$. Hitherto/span>, there has been no specific information in Botswana regarding the rate of CS, description of categories of CS or type of anaesthesia used for CS. Therefore, this study aimed to determine: (1) The type of anaesthesia used for CS among live-birth deliveries, general or regional, stratified by urgency, elective and emergency, in Princess Marina Hospital (PMH), in Botswana; (2) Failure rate of regional anaesthesia requiring a shift to general anaesthesia.

\section{Methods}

\section{Study population}

All mothers who delivered with the help of CS under anaesthesia during the study period.

\section{Study settings}

The study was conducted in PMH, in Gaborone, Botswana. PMH is one of the largest public referral hospitals in Botswana with just over 500 beds and six operating theatres. Patients are commonly referred from smaller district hospitals and outreach clinics to $\mathrm{PMH}$ for specialized or advanced care.

\section{Data collection}

Data were collected using the PMH anaesthesia register between May and December 2017. Data were double-entered into a Microsoft Excel (2013) Spreadsheet. Inconsistencies and missing data were identified through logic checks, and once identified data were checked against the original anaesthesia register. The variables included were the age of the patient, indication for CS, the urgency of the CS, mode of anaesthesia and time taken to conduct the CS procedure. Medications, such as oxytocin and vasopressors, were also recorded.

\section{Definition of terms}

CS is when a baby is born through an incision in the mother's abdomen and uterine wall. Elective is when CS is planned and an Emergency when CS is not planned ${ }^{11}$. Regional anaesthesia refers to the use of local anaesthetic solutions to produce circumscribed areas of loss of sensation. The types of regional anaesthesia used for CS that is, spinal (subarachnoid) and epidural (extradural) anaesthesia involve the infiltration of a local anaesthetic agent, usually bupivacaine, into the surroundings of the spinal cord through the lower back of the woman. General anaesthesia refers to the loss of ability to perceive pain associated with loss of consciousness produced by intravenous or inhaled anesthetic agents ${ }^{23}$.

\section{Classification of CS Categories ${ }^{24}$}

CS category. A classification relating the degree of urgency of CS to the presence or absence of maternal or fetal compromise.

Category $1=$ immediate threat to the life of mother or fetus

Category 2 = no immediate threat to the life of mother or fetus

Category $3=$ requires early delivery

Category $4=$ at a time to suit the women and staff (elective)

\section{Statistical Analysis}

Data were analyzed using STATA (Stata Corp. 2015. Stata Statistical Software: Release 14. College Station, TX: Stata Corp LP) ${ }^{25}$. We established the type of anaesthesia used, comparing the rate of elective versus emergency indications, and conversion rate from SA to GA (failure rate of SA) using STATA. In our comparison, we used Chi-square or Fisher's exact test and $\mathrm{P}$ values of $<0.05$ were considered statistically significant.

\section{Ethical considerations}

The study protocol was approved by the University of Botswana Institutional Review Board (UBR/RES/ IRB/17552), Botswana Health Research and Development Committee of Ministry of Health and Wellness (HDME: 13/18/1VoLX (81), and PMH and Ethical Committee (5/79(306-1-2017). Waiver for the informed consent process was offered by the IRBs. 
Results

Among 2775 live-birth deliveries conducted in $\mathrm{PMH}$, $30.2 \%(837 / 2775)$ was conducted using CS, the median age and interquartile range (IQR) among 837 was 29 years (IQR, 24-29 years).

Type of anaesthesia by elective versus emergency CS

Out of 837 live-birth, SA was the initial choice of anaes- thesia for 813 of the CS while for 24 GA was an initial choice. For 16 (2 from elective and 14 from emergency group) CS aesthesia choice was changed from SA to GA during the CS procedure. Excluding the 16 changed from SA to GA, overall, elective CS was performed under SA in 27.4\% (218/797) versus 10.0\% (4/40) under GA, Fisher's exact test $\mathrm{p}<0.016$. Emergency CS was performed under $\mathrm{SA}$ in $72.6 \%(579 / 797)$ versus $90.0 \%$ (36/40) under GA (including those converted from SA to GA), Fisher's exact test $\mathrm{p}<0.016$ (Fig. 1).

Fig 1. Flow diagram type of anaesthesia for caesarean section and indication status, elective versus emergency

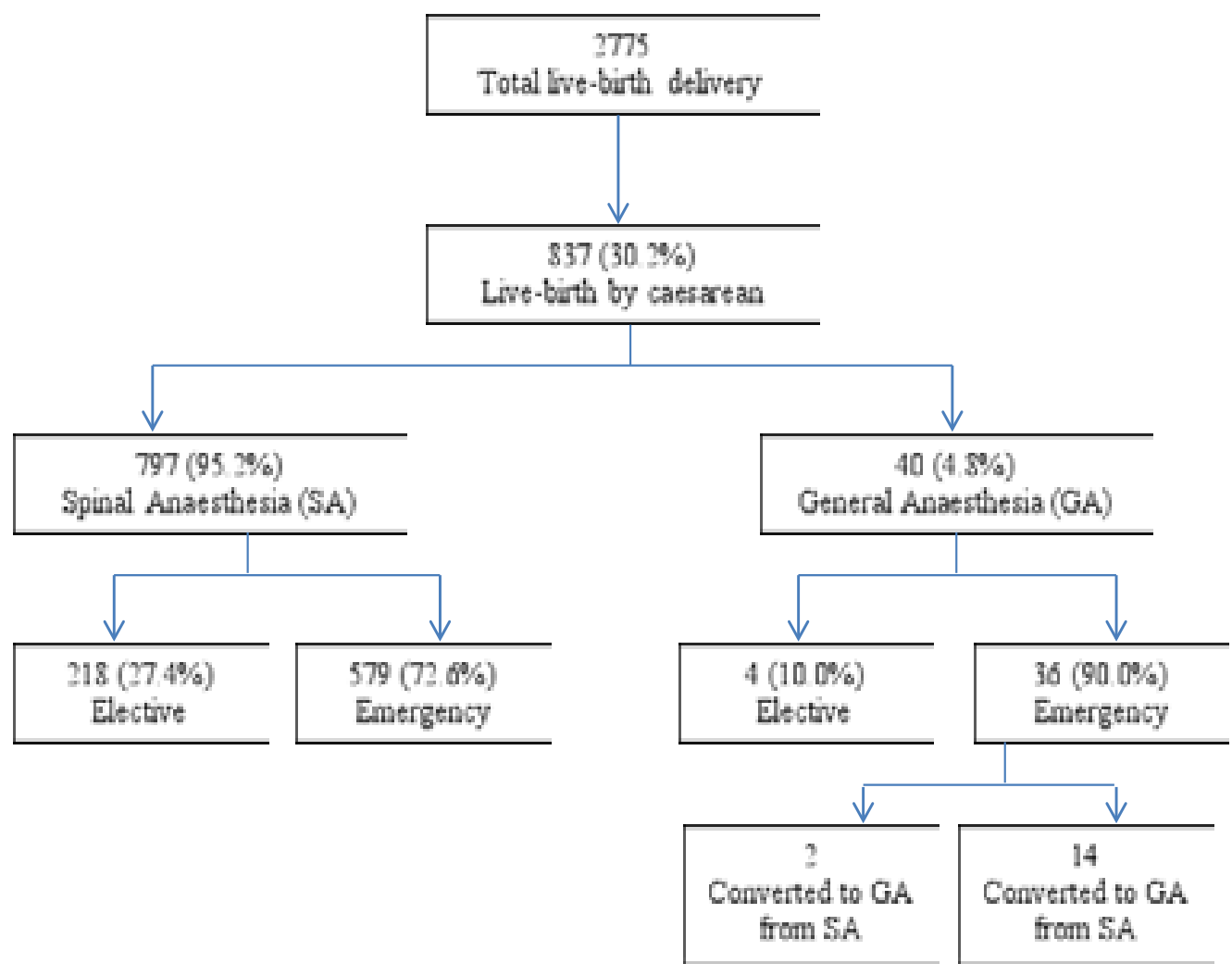

Note: Elective CS was performed under SA in $98.2 \%(218 / 222)$ versus $1.8 \%(4 / 222)$ under GA, and Emergency CS performed under SA in $94.1 \%(579 / 615)$ versus $5.9 \%(36 / 615)$ under GA

\section{Conversion to General from Spinal Anaesthesia}

Overall 2.0\% (16/813) of CS under SA converted to GA during the CS procedure. The failure rate was higher, though it did not reach a significant level, among
CS deliveries with emergency indication than elective CS indications, $2.4 \%(14 / 593)$ versus $0.9 \%(2 / 220)$, respectively, Fisher's exact test $\mathrm{p}=0.2959$ (Table 1). Bupivacaine was the only available local anesthetic used for spinal anaesthesia in our context. 
Table 1. Failure rate of spinal aesthesia requiring change to general anaesthesia between elective and emergency cesarean section procedure

\begin{tabular}{lllll}
\hline \multicolumn{5}{c}{ Initial use of Spinal Anaesthesia } \\
\hline Type of CS* & Failed** & Successful & Row total & Fisher's exact test, \\
& & & & $p$ value \\
\hline Elective CS & $2(0.9 \%)$ & $218(99.1 \%)$ & 220 & 0.2959 \\
Emergency CS & $14(2.4 \%)$ & $579(97.6 \%)$ & 593 & \\
\hline Column total & 16 & 797 & 813 & \\
\hline
\end{tabular}

* CS $=$ Cesarean section

** Failed means conversion to general anaesthesia from initial spinal anaesthesia

Indications for caesarean section conducted under as a result of failed spinal anaesthesia, 40\% (16/40), folgeneral anaesthesia in Princess Marina Hospital in lowed by antepartum hemorrahage, 22.5\% (9/40) and Botswana

Out of 40 CS performed under GA, the majority were (Fig. 2).

Fig 2. Indications for caesarean section conducted under general anaesthesia in Princess Marina Hospital in Botswana

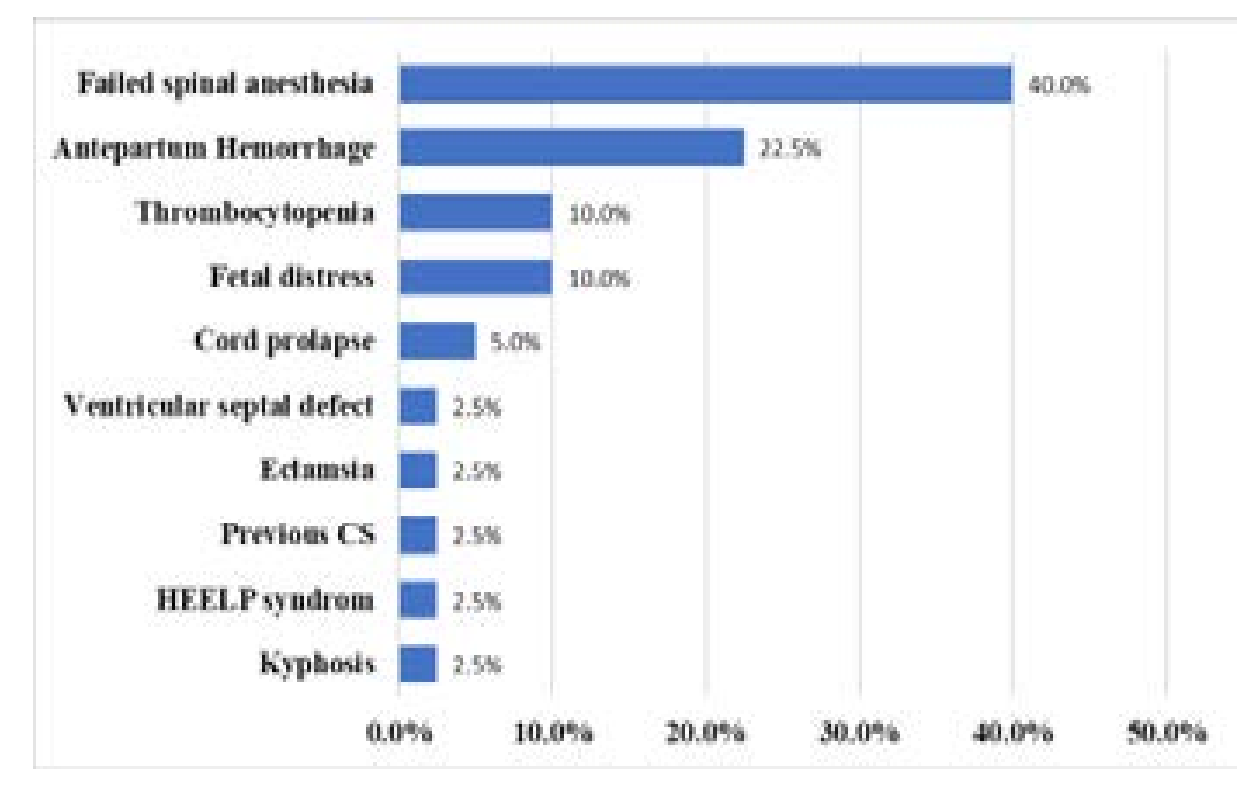

Note: $\mathrm{CS}=$ caesarean section

Indications for caesarean section conducted as an post-date pregnancy and big-baby were in the top three, elective in Princess Marina Hospital in Botswana $\quad 55.9 \%$ (124/222), 10.8\% (24/222) and 8.1\% (18/222), Among the 222 performed as elective CS, previous CS, respectively (Fig. 3). 
Fig 3. Indications for caesarean section conducted as an elective in Princess Marina Hospital in Botswana

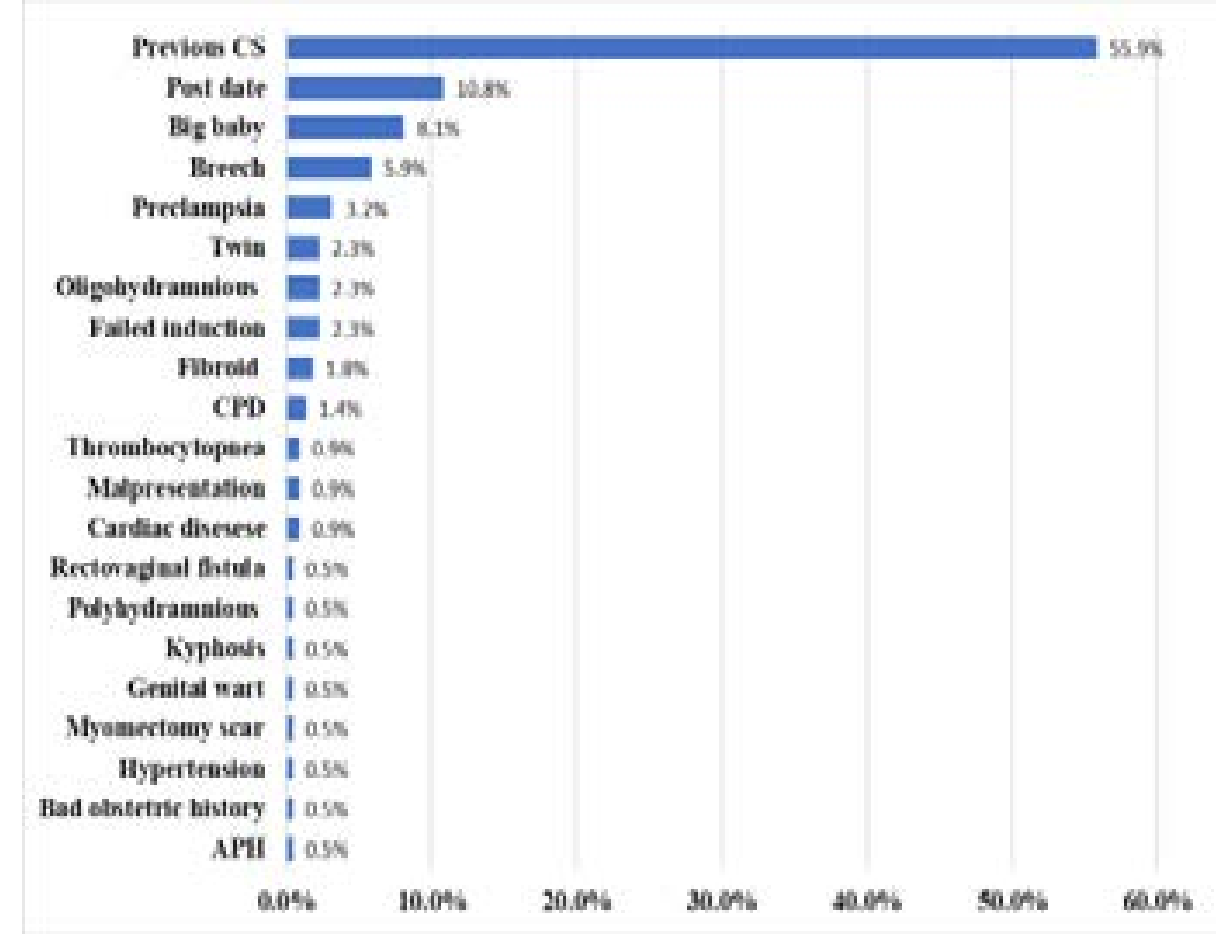

Note: $\mathrm{APH}=$ Antepartum hemorrahage, $\mathrm{CS}=$ caesarean section, $\mathrm{CPD}=$ Cephalopelvic disproportion

\section{Category of caesarean section and spinal anaes- thesia}

Category $1 \mathrm{CS}$ is an immediate threat to the life of a woman or fetus, and 205 cases were category 1 . Among this $89.3 \%(183 / 205)$ CS performed under spinal anaesthesia and the remaining $10.7 \%$ were under general anaesthesia. The indications for Category 1 CS were: Imminent uterine rupture, Antepartum haemorrhage, Fetal distress and Cord prolapse.

\section{Spinal bupivacaine $0.5 \%$ doses and other drugs used for CS \\ The bupivacaine doses used for CS ranged from $7.5 \mathrm{mg}$ to $15 \mathrm{mg}$, and the majority used $12.5 \mathrm{mg}(81.3 \%$, $648 / 797)$ followed by $10 \mathrm{mg}(13 \%, 103 / 797), 12 \mathrm{mg}$ (3.3\%, 26/797), $15 \mathrm{mg}(0.9 \%, 7 / 797), 11 \mathrm{mg}(0.6 \%$, 5/797), $9 \mathrm{mg}(0.4 \%, 3 / 797), 8 \mathrm{mg}(0.3 \%, 2 / 797), 13 \mathrm{mg}$ $(0.3 \%, 2 / 797)$ and $7,5 \mathrm{mg}(0.1 \%, 1 / 797)$.}

There was no epidural or combined spinal-epidural performed during the study period for CS. Hyperbaric bupivacaine was used combined with fentanyl in $20 / 797(2.5 \%)$ cases and the most commonly used dose was $12.5 \mathrm{mg}(81.3 \%)$. And $10 \mathrm{mg}$ used in $103(12.9 \%)$ of women. The common dose used ranged from 10 $12.5 \mathrm{mg}$. The lowest dose was $7.5 \mathrm{mg}$ and the highest being 15mg. Vasopressor was required to treat spinal hypotension in 150/837(18.97\%) cases. Pharmacologic agents used to treat spinal hypotension and bradycardia were phenylephrine, ephedrine and atropine. Ten IU intravenous bolus of oxytocin used to augment uterine contractions in all cases.

Analysis of different grades of CS showed 205 category 1 CS such as 139 fetal distress, 43 antepartum haemorrhages, 16 imminent uterine rupture, and seven cord-prolapse.

\section{Discussion}

The present analysis was the first study reporting on type of anaesthesia, general or regional, stratified by elective and emergency, and the prevalence of CS in referral hospital settings in Botswana. Close to onethird $(30.2 \%)$ of deliveries in PMH was by CS which is on the higher side of what is estimated worldwide. Globally, though CS rate increased even up to $30 \%$, the WHO emphasise that at a population level, CS rates higher than $10 \%$ are not associated with reductions in maternal and newborn mortality rates benefit for women or infants being the major reasons for considering CS deliveries. Currently, there is no standard classifica- 
tion system for CS that would allow the comparison of CS rates across different facilities, cities, countries or regions in a useful and action-oriented manner ${ }^{26}$. A population-based recommended CS rate cannot be applied as the ideal rate at the hospital level ${ }^{26}$ and thus our hospital-level result was not directly comparable to any other study.

Given the benefits and risks of the different techniques, it is important to clarify what type of anaesthesia is more efficacious in terms of various maternal and neonatal outcomes for the different types of, and indications for, CS ${ }^{11}$. In our settings, $98.2 \%$ of elective and $94.1 \%$ of emergency CS was conducted using regional (SA) anaesthesia which is higher than the report from sub-Sahara countries $\left(80-90 \%\right.$ of CS under SA) ${ }^{21}$. The present finding was also higher than the minimum practice from high-income countries, where the rate was $95 \%$ and $85 \%$, respectively for elective and emergency $\mathrm{CS}^{27}$. In this study, we observed that spinal anaesthesia was used frequently for category $1 \mathrm{CS}$ which contributed to a high percentage of spinal anaesthesia for emergency CS.

In this study, there was no epidural or combined spinal-epidural anaesthesia usage as a mode of anaesthesia for CS. Partly, the reason was due to lack of labour analgesia set up in $\mathrm{PMH}$ and partly because of the shortage of trained nursing staff in the maternity ward to monitor the patient.

In $\mathrm{PMH}$, there is no protocol on a type of anaesthesia for the different category of CS. In this study, we observed that SA used frequently for category 1 CS that most likely contributed to the high percentage of SA for emergency CS (96\%). In our study, the finding of the high percentage of SA for category I emergency CS is above the minimum of the high-income countries in some cases like uterine rupture and cord prolapse may also contribute to this finding.

In contrast to reports from Nigeria and South Africa, the rate of failure of the $\mathrm{SA}$ and subsequent conversion to GA in PMH is low $(0.9 \%$ among elective and $2.4 \%$ among emergency CS, Table 1). A study in Nigeria revealed a SA failure rate of $6 \%$ which was attributed to technical failure as it was found to occur with anaesthetists who had low experience in anaesthesia ${ }^{28}$. South African family medicine practice has revealed the incidence of a SA failure rate as high as $11 \%$ \& found to be higher in emergency CS. From another South Africa report in Mthatha hospital, the incidence of a SA failure was $11.7 \%$ with a higher rate for emergency (12.3\%) than with elective $(9.4 \%)$ CS $^{29}$. According to the Royal College of Anaesthetists (2012), a 1\% failure rate for elective and 3\% for emergency CS are acceptable ${ }^{27}$. The present study findings showed that the incidence of failed SA was lower in PMH compared to that of the South African Eastern Cape Mthatha hospital, Nigeria or the Royal College of Anaesthetist's practice/experience. In our settings, GA conversion from SA was seen in both high and low doses of bupivacaine $(0.5 \%)$. As the SA failure was seen with a high and low dose of bupivacaine and we are in agreement with the report from Nigeria that attributed technical problems with less experience.

Opioid adjunct to SA during CS has the advantage of increasing the intraoperative sensory block and the quality of analgesia. The synergetic effect of an opioid will aid to decrease the dose of bupivacaine required for SA and it helps to decrease the risk of high block or spinal hypotension ${ }^{30}$. Concerning the use of adjuvant during $\mathrm{CS}$ anaesthesia in $\mathrm{PMH}$, fentanyl was the only drug used. This result showed the use of fentanyl adjuvant during SA for CS was in 20 parturient cases $20 / 797(2.39 \%)$ which is a very low percentage. In our entire patient population, the local anaesthetic used for SA was bupivacaine $0.5 \%$. A variety of bupivacaine dosing regimens was used in our settings. In most cases, the dose of bupivacaine for SA in PMH was $12.5 \mathrm{mg}$. Some authors suggest the bupivacaine dose commonly used is slightly higher than the average dose reported ${ }^{18}$. Adjusting the spinal bupivacaine dose to patient height is the factor that should be taken into consideration in order to decrease the incidence and severity of hypotension and less requirement of vasopressors ${ }^{31}$.

Oxytocin initial bolus dose can cause cardiac arrhythmia and hypotension. It is essential to take precaution especially in those parturient with hemodynamic instability and cardiac illness. All our patients received an initial bolus dose of $10 \mathrm{IU}$ regardless of the comorbid condition and indication for CS while the 2010 British Journal of Anaesthesia has concluded the routine use of 5 units oxytocin bolus during elective $\mathrm{C}$-section can no longer be recommended as adequate uterine tone can be obtained with lower doses of oxytocin (0.5 $3)^{32}$. The study by Tsima et al in 2013 at PMH on the use of oxytocin during CS revealed that the local setting does not follow international practice and recommended the need for national guidelines ${ }^{33}$. According to the 
2017 Up-to-date, oxytocin bolus should be given slowly in a dose of less than $3 \mathrm{IU}^{18}$.

Our study has some limitations. First, the study was cross-sectional in one referral hospital, as the result would only reflect a snapshot of CS in PMH, not at the country level. However, PMH being the largest public referral hospital in Botswana, and most deliveries being at health facilities our result would be helpful to program implementation and future planning. Second, there was no detailed profile on comorbidity and obstetric complications; and there was no maternal or neonatal outcome included since there was no follow up of patients after the procedure.

\section{Conclusion}

Our study demonstrated that single shot SA is the most commonly preferred mode of anaesthesia for both elective and emergency CS in PMH in Botswana that is higher than that of practices in sub-Sahara African countries. The SA failure rate and subsequent conversion to GA were less than the rate mentioned in the literature for both emergency and elective CS. Regardless of the indication for CS or considering the presence or absence of comorbid conditions $10 \mathrm{IU}$ of oxytocin given as a bolus intravenously in all cases that is a high dose. A prospective comprehensive study including assessment of maternal and neonatal outcomes associated with the choice of anaesthetic technique is warranted.

\section{Acknowledgments}

This work has been supported by the faculty of Medicine, University of Botswana.

The findings and conclusions in this report are those of the authors and do not necessarily represent the official position of the funding agency or organization. We also extend our gratitude to Dr. Mokone G.G for his contribution towards organization and editing the manuscript.

\section{Sources of support}

This research has been supported by the faculty of Medicine, University of Botswana.

\section{Disclaimer}

The findings and conclusions in this report are those of the authors and do not necessarily represent the official position of the funding agencies.

Author contributions

MWK, JM, and TA designed the study. MWK conducted the fieldwork and data collection. MWK and
TA conducted statistical analyses. MWK, JM, JZS, and TA reviewed the data collected and participated in the writing of the results. All co-authors contributed to the writing of the manuscript.

\section{Conflict of interest}

All authors have no conflict of interest.

\section{References}

1. Hannah ME, Hannah WJ, Hewson SA, Hodnett ED, Saigal S, Willan AR. Planned caesarean section versus planned vaginal birth for breech presentation at term: a randomised multicentre trial. Lancet. 2000;356:1375-83 PubMed . doi:10.1016/S0140-6736(00)02840-3.

2. Betran AP, Torloni MR, Zhang J, Ye J, Mikolajczyk $\mathrm{R}$, Deneux-Tharaux $\mathrm{C}$, et al. What is the optimal rate of caesarean section at population level? A systematic review of ecologic studies. Reprod Health. 2015;12.

3. Betrán AP, Ye J, Moller AB, Zhang J, Gülmezoglu AM, Torloni MR. The increasing trend in caesarean section rates: Global, regional and national estimates: 1990-2014. PLoS One. 2016;11:1-12 PubMed .

4. Harrison MS, Goldenberg RL. Cesarean section in sub-Saharan Africa. Matern Heal Neonatol Perinatol. 2016;2:1-10. doi:10.1186/s40748-016-0033-x.

5. Victora CG, Barros FC. Beware: unnecessary caesarean sections may be hazardous. Lancet. 2006.

6. Steer PJ, Modi N. Elective caesarean sections-risks to the infant. Lancet. 2009;374:675-6 PubMed .

7. The Lancet. Caesarean section-the first cut isn't the deepest. Lancet. 2010;375:956.

8. Mi J, Liu F. Rate of caesarean section is alarming in China. Lancet. 2014;383:1463-4 PubMed .

9. Sufang G, Padmadas SS, Fengmin Z, Brown JJ, William Stones R. Delivery settings and caesarean section rates in China. Bull World Health Organ. 2007;85:755-62. 10. Sia ATH, Fun WL, Tan TU. The ongoing challenges of regional and general anaesthesia in obstetrics. Best Pract Res Clin Obstet Gynaecol. 2010;24:303-12.

11. Afolabi BB, Lesi FEA, Merah NA. Regional versus general anaesthesia for caesarean section. Cochrane Database Syst Rev. 2006.

12. Rollins M, Lucero J. Overview of anesthetic considerations for Cesarean delivery. $\mathrm{Br}$ Med Bull. 2012;101:105-25 PubMed.

13. Attwood C. Safer caesarean sections at Juba Teaching Hospital. South Sudan Med J. 2012;5:39-42 PubMed -42 .

14. Jadon A. Complications of regional and general anaesthesia in obstetric practice. Indian J Anaesth. 2010; 54:415-20 PubMed. doi:10.4103/0019-5049.71039. 
15. Djabatey EA, Barclay PM. Difficult and failed intubation in 3430 obstetric general anaesthetics. Anaesthe sia. 2009;64:1168-71.

16. Bucklin BA, Hawkins JL, Anderson JR, Ullrich FA. Obstetric anaesthesia workforce survey: Twenty-year update. Anesthesiology. 2005;103:645-53 PubMed .

17. Berghella V. Cesarean delivery: Preoperative planning and patient preparation. In: Lockwood JC, Barss AV, editors. UpToDate. Waltham, MA (Accessed on August 3, 2017); 2017.

18. Nixon H, Leffert L. Anaesthesia for cesarean delivery. In: UpToDate. Waltham, MA (Accessed on August 3, 2017); 2017.

19. Yeoh SB, Leong SB, Heng AST. Anaesthesia for lower-segment caesarean section: Changing perspectives. Indian J Anaesth. 2010;54:409-14 PubMed . doi:10.4103/0019-5049.71037.

20. Banks A, Levy D. General anaesthesia for operative obstetrics. Anaesth Intensive Care Med. 2007;8:317-9. doi:10.1016/J.MPAIC.2007.05.007.

21. Fyneface-Ogan S. Anaesthesia for Cesarean Section. In: Salim R, editor. Cesarean Delivery. $1^{\text {st }}$ edition. Rijeka: InTech; 2012.

22. Moore B. Appropriate technology for birth. Lancet. 1985;326:787. PubMed doi:10.1016/S01406736(85)90673-7.

23. Thorburn J. Obstetric anaesthesia and analgesia. In: Aitkenhead A, Smith G, editors. Textbook of Anaesthesia. 3rd edition. London: Churchill Livingstone; 1998. p. 533-50.

24. Lucas DN, Yentis SM, Kinsella SM, Holdcroft A, May AE, Wee M, et al. Urgency of caesarean section: A new classification. J R Soc Med. 2000;93:346-50 PubMed .

25. StataCorp. Stata Statistical Software: Release 14. College Station, TX: StataCorp LP: 2015.
26. World Health Organization, Human Reprodcutive Programme. The World Health Organization statement on Cesarean Section Rate. Sexual and reproductive health. 2015. https://www.who.int/reproductivehealth/publications/maternal_perinatal_health/ cs-statement/en/. Accessed 3 Jan 2019.

27. Royal College of Anaesthetist. Technique of anaesthesia for Caesarean section. In: Colvin DJR, Peden DCJ, editors. Raising the Standard: A Compendium of Audit Recipes. $3^{\text {rd }}$ edition. London: The Royal College of Anaesthetists; 2012. http://www.rcoa.ac.uk/index. asp. Page ID=125. Accessed on 03 Jan 2019.

28. Adenekan A, Olateju S. Failed spinal anaesthesia for caesarean section. J West African Coll Surg. 2011;1:117 PubMed . https://www.ncbi.nlm.nih.gov/pubmed/25452968.

29. Alabi AA, Adeniyi OV, Adeleke OA, Pillay P, Haffajee MR. Factors associated with failed spinal anaesthesia for caesarean sections in Mthatha general hospital, Eastern Cape, South Africa. South African Fam Pract. 2017;59:128-32. doi:10.1080/20786190.2017.1292696. 30. Turhanoglu S, Kaya S, Erdogan H. Is there an advantage in using low-dose intrathecal bupivacaine for cesarean section? J Anesth. 2009;23:353-7 PubMed .

31. Siddiqui KM, Ali MA, Ullah H. Comparison of spinal anaesthesia dosage based on height and weight versus height alone in patients undergoing elective cesarean section. Korean J Anesthesiol. 2016;69:143-8.

32. Butwick AJ, Coleman L, Cohen SE, Riley ET, Carvalho B. Minimum effective bolus dose of oxytocin during elective Caesarean delivery. BJA $\mathrm{Br} J$ Anaesth. 2010;104:338-43. doi:10.1093/bja/aeq004.

33. Tsima BM, Madzimbamuto FD, Mash B. Use of oxytocin during Caesarean section at Princess Marina Hospital, Botswana: An audit of clinical practice. African J Prim Heal Care Fam Med. 2013;5:30-5. 